\title{
SYMBOLIC CULTURE AND IMAGINAL PRACTICES FOR EDUCATIONAL AND CARE PROFESSIONALS: AN INTERVENTION RESEARCH IN THE FIELD OF HEALTH EDUCATION
}

\author{
Marina Barioglio, Paolo Mottana \\ Milano Bicocca University (ITALY)
}

\begin{abstract}
Introduction The importance of introducing mythopoetic practices in adult's and professional education is supported by many thinkers (Durand, Hillman, Zambrano, Leonard, Willis). In Italy this exigency comes from the awareness of the contamination of educational culture by imaginary, ideas that psychological, social, technical disciplines offer of its great topics and problems (Mottana). The presence of these disciplines is evident in Health Pedagogy with the great advantage to assure clear references, useful operative strategies or protocols helping who works in sanitary services. But often the trend is to abuse of technical categories, produce classifications of therapeutics, assistance and educative experience using reductive interpretations or languages, reducing sensitive and imaginative ability of professionals who seem to recognise their identity only in patterns based on competence systems or job description. What we need then is also an improvement of sensibility, an enrichment of imaginary and patterns of understanding and we can reach this goal applying to the artistic creations coming from the huge mythical basin of our tradition.
\end{abstract}

Methodology: This paper aims to give account of a concrete research and educational experience conducted with the mythopoetic approach of Imaginal Pedagogy" (Mottana) involving clinical tutors in the field of Health Education at Turin's University (4 educational interventions from 2014 to 2016). Each path lasted 3 days of 7 hours in which participants (groups of 15 clinical tutors chosen for their educative experience) were asked to reflect on the figure of clinical tutor moving from their own imaginary but going beyond it through the exploration of symbolic works of art. According to the imaginal approach works were treated as sources from which to distil knowledge, as living subjects with a particular physiognomy and pregnant with meaning using a respectful hermeneutic based on contemplation, listening, loyalty to the image, suspension of judgement. In spite of the difficulty of the the exploration and the density of the works of art presented the participants appeared sensitive and eager to learn a different may of reading images and experience, eager to sick a methodology so distant from their usual habit; they have absorbed, reflected imaginal experience of the works patiently showing a good ability to dwell into the abyss of contradictory meanings.

Results: At the end of the work each group tried to give some interpretations of the works of art, distil a new different knowledge about tutor figure coming to symbolic interpretations. Without coming to definitive explanations, they succeeded in identifying possible meanings, naming resonances, recognising correspondences between the explored matter and the world of symbols, archetypes the works referred to. At the end sparks of knowledge appeared, something different than a corpus of notions, concepts or competences. Perhaps they don't learn something more on tutor but their sensibility in regard of this educative figure became deeper, more complex as it appears in the final symbolic pictures they produced. The participants gained a particular kind of knowledge, something different from the ordinary corpus of notions, concepts or competences. They have learnt neither something more on tutoring nor new techniques of tutoring but their sensibility in relation to these experiences became deeper and even more exact as it appears in many final pictures they produced. But the most important result is to be found in the acknowledgement of the imaginal art world as a world of knowledge, a huge cultural heritage of symbols and myths coming from a tradition of centuries, able to enrich their professional background.

Conclusions. These results suggest once more that the imaginal approach can be successfully employed even in the medical educational field, and that the symbolic art it refers to is not just a "didactic tool", but an important cultural spring from which to draw water to revitalise our culture.

Keywords: Symbolic culture, imaginal education, health education. 


\section{INTRODUCTION}

During the last centuries the lack of symbolic imagination in life and culture was denounced by several thinkers and scholars coming from different fields of knowledge (philosophers, anthropologists, psychologists, educators and even physicians) who saw in this phenomenon the consequence of a loss of sense and deepness of life and experience, an impoverishment of culture, of human relationships, and of professional participation. Sometimes this denounce was stronger by the side of those professions or those scholars who were mostly engaged in the cure of human beings or in their taking care. So a psychiatrist such as Carl Gustav Jung argued that the lack of imagination was the most important causes of psychological sufferings and that it affected the patient as well as his/her healer or car-giver. This thesis is supported by many other thinkers and therapists who, in different ways, tried to explore the way to restore the symbolic function in order to promote the recovery of their patients. Important form this point of view are the practices of "active imagination" created by Jung and his prosecutors, the "soul-making" exercises by James Hillman, the "guided day dream" by Desoille and Yves Durand or the several art approaches in the field of therapeutic studies. All these practices are very effective and produce many successes, but they have the limit to be employed only in the field of individual therapy. As Gaston Bachelard, Gilbert Durand, James Hillman, Jean Jacques Wunenburger argued what we need is not only a individual therapy, but a collective one, or better, we need an imaginative revolution in our culture, in all the fields of human knowledge and experience. So we need a pedagogy of imagination, we need spaces, times, methodologies, contents to help people to awake their imaginative sensibility, to improve their mythopoetic attitude that is the ability to perceive and recognise the invisible face of the world, the deep symbolic dimension of all its phenomena, objects, situations, events and living being. All over the world the importance of introducing mythopoetic practices in the education of children but also in adult's and professional education is supported by several pedagogical thinkers such as Timothy Leonard and, John Dirkx, Mary Doll in the USA, Peter Willis, Peter Bishop, James Bradbeer, Rod Fawns in Australia, Patricia Cranton, Leona M. English in Canada, Bruno Duborgel in France. In Italy this exigency comes from the awareness of the contamination of educational culture by imaginary, ideas that psychological, social, technical disciplines offer of its great topics and problems (Mottana 2000). The presence of these disciplines is also evident in Health Pedagogy where it has the great advantage to assure clear references, useful operative strategies or protocols helping who works in sanitary services. But often the trend is to abuse of technical categories, produce classifications of therapeutics, assistance and educative experience using reductive interpretations or languages, reducing sensitive and imaginative ability of professionals such as doctors, nurses, educators and clinical tutors who seem to recognise their identity only in patterns based on competence systems or job description. What we need then is an improvement of sensibility, an enrichment of imaginary and patterns of understanding and we can reach this goal applying to the artistic creations coming from the huge mythical basin of our tradition. This means to acknowledge and ponder great topics of educational or care experience throughout some of their expressions in arts, literature, cinema, in order to vitalize the screen on which re-learn to see, perceive, even before, operate.

Starting with this exigence at the beginning of the XXI century Paolo Mottana published two important books about a concrete proposal for a pedagogy of imagination: L'opera dello sguardo (2002) in which, with the help of Bachelard, Durand, Jung, Hillman, Corbin, Bonardel, Wunenburger and the alchemic tradition, he supports the reasons of the imaginative thought for understanding the world and living in it a more participative and responsible way, and La visione smeraldina (2004) in which he explains how to create an imaginative pedagogical setting, and propose a methodology to guide adults in the search of their symbolic sensibility helped by the mentoring of deeply symbolic works of art (movies, poetries, music, pictures). Prerogative of this imaginal approach is to renounce what is already known, to give up the accustomed knowledge we use to read and understand the experience, in order to plunge into a rich and thick symbolic texture which allows us to get away from usual categories and technical terminologies about educational and heath topics, themes and problem of particular social, political, therapeutic and assistive relevance. In this way, for example, areas of experience regarding our body, health, disease, suffering, live, sex, (and their education) can be understood not only through the theories of sanitary, biological, psychological or moral disciplines but can be re-imagined through the works by Garcia Lorca, Neruda, Plath, Pozzi, Hillesum, the pictures by Much, Masson, Bacon, Valls, Rouault, Freud, Music, Khalo, the drawings by Balthus, the movies 
by Resnais, Tarkovskij, Almodovar, Kim-Ki-duk, Von Triar, Kawase, Wildt, the music by Scelsi or Sophia Gubaidulina. ${ }^{1}$

In the field of Health education some imaginal experience were done around the archetypal experience of the "wound", "pain" "loss"," mourn" "sickness and healing", "death and re-birth", "ascending and descending". In some imaginal paths of the last years involving nurses, physicians, car-givers the participants were directed towards the meditation on sickness, death and grief through Bacon's dissipating paintings, Music's transforming paintings or Soutine's distorting landscape and Vall's tormented bodies; through the intense poetry by Sylvia Plath and Antonia Pozzi and the movies Mogari no Mori by Naomi Kawase. (Barioglio 2011, 2015). An equally important experience was the research of the mythical figures lying inside the medical and assistive profession such as the Healer or the medicine woman, the Wizard and the Sorceress or some educational outsiders such as the Mentor. ${ }^{2}$ The Mentor is an educational figure of ancient and illustrious genealogy, of great tradition and symbolic meaning deepness for what it concerns the initiatory and transformative meaning and very important in everybody's educational story. But nowadays this figure often seen a a trainer or a coach appears in our professional health educational programs in a domesticated version often fettered by the logic of the organisation.

Recently the symbolic figure of Mentor has been successfully revived during an imaginal education experience involving clinical tutors and educators coming form the Degree Course of Nursing Disciplines at Turin University about which we would like to give account in the following paragraphs.

\section{METHODOLOGY}

These paragraphs aim to give account of a concrete research and educational experience conducted with the mythopoetic approach of Imaginal Pedagogy" (Mottana 2002, 2004, 2010; Barioglio 2009, 2014) involving clinical tutors in the field of Health Education at Turin's University. The full programme consisted in four 4 educational interventions from 2014 to 2016. Each path lasted three days of seven hours in which participants (groups of 15 clinical tutors chosen for their educative experience) were asked to reflect on the figure of clinical tutor and its relationship with the mythic figure of the Mentor moving from their own imaginary but also going beyond it through the exploration of symbolic works of art. (i.e the movie Anni luce by Alain Tanner, the movie An officier and a Gentleman by Taylor Hackford, the movie The Guardian by Andrew Davis, the short story Manovre di volo and Per l'errore by Del Giudice).

According to the imaginal approach the participant were introduced in a pedagogical space called "clearing" through an evocative music by Brian Eno and after a brief introduction they were put in direct contact with the chosen art works to be treated as sources from which to distil knowledge, as living subjects with a particular physiognomy and pregnant with meaning using a respectful hermeneutic.

The training adhered to the imaginal methodology (Mottana 2004,2010, Barioglio 2010, 2014), which is not a "method" in the strict sense of the word, but a corpus of recommendations such as "loyalty to image", "suspension of judgement" and "extroversion", with the aim of inducing the same attitude the artist had assumed while producing the work. It is also a symbolic corpus made of operations and work phases that analogically recall alchemy opus, inspired by its metaphors, its language, its colours, its tinctures; contributing to dislocate into the images world and to explore it, giving up all their technical, psychological, sociological and even biographical categories; even renouncing to express and talk about their own experiences or feelings.

After an intense "vision" of each work of art, the participants were addressed to an individual "meditation". This means they were asked to ponder on it, to re-evocate it and then describe for the group its shapes, its figures. After this first reconstruction they were asked to return to the work and to "dwell" upon it in order to live an "experience of the image within the image", to perceive and reflect, to recognise its feature, its geography and its specific geology: to dwell upon the work listening and listening to its voice, looking and looking at it in order to allow it to portray itself.

\footnotetext{
The imaginal exercises can interest very many archetypal basins: the elements (water, fire, air and earth), the figures of nature (the sun, the tree, the moon), the metaphoric representation of ascending and descending, the experience of being sick, wounded, abandoned; love, sex; the season of life; the symbolic images of parents, pf the healer, the teacher, the mentor, of the wizard, of the witch, of hero and so on.

2 About the symbolic character of the Mentor see also Mottana P. II mèntore come antimaestro, Clueb 1996; and Saggi ipocriti mèntori in Antipedagogie del piacere, Angeli, Milano 2008 pp. 53-61;
} 
They were also encouraged to "walk" into it with the interest and passion they would have for an unknown, mysterious and charming place, looking for what is less visible, for what is fleeting, for the connections of its parts, for the details, for shapes and figures. This means adopting from the very beginning a sensitive, participative, feminine style of exploration, rooted in figures of intimacy with the matter explored, together with complicity, respect, obscurity, intense listening.

Little by little this exercise, which is the imaginal hermeneutic experience at its first step and which is like an alchemic nigredo, allowed the participants to dissolve and re-dissolve prejudice, precomprehensions, their medical, moral, psychological categories, and to modify the usual dominant posture of our culture. Disoriented and lost in the work of art at first, even abandoning their usual specialistic terminology, they found themselves in the condition of a "dumb man" and felt obliged to find new and different words to name what was appearing, to acknowledge images, to designate tutor's knowledge, activities, attitude, tools, sensibility, duty, emotions. They were forced to find more and more sticky words to answer to the images.

This process opened a phase of albedo in which, for example, the strange character of the old Yoshka appearing in the movie Anni Luce showed its mythic and symbolic rooting advocating the archetypal figure of the Mentor not as a wise man but as an Old fool (as Guggenbühl-Craig would say) and became an hermetic guide for the educative initiation of the young Jonas.

Something similar happened in reading the short stories by Daniele del Giudice, listening to the pervading deepness, ambiguity of the fascinating figure of Bruno, the flying instructor, deeply connected with the imaginal characters of an Indian chief, an Augur, an extremely experienced airplane-pilot and at the same time a common man, short and little bit fat, loving good food and, a loving family father and and very intuitive gay, keeper (and for this reason also teacher, or better mentor) of a particular kind of understanding strictly connected with the knowledge of nature; a kind of metis, a kind of sensibility and intuitive perception very close to the poetic attitude that shows itself to be necessary to manage in difficult and delicate situation such as flying... and also curing, teaching, taking care, living.

\section{RESULTS}

In spite of the difficulty of the exploration and the density of the work of art presented, all participants appeared sensitive and eager to learn a different way of exploring images and experience. They were willing to stick to a methodology very distant from their usual habit. They absorbed, pondered and reflected the imaginal experience of the works of art, respectfully and patiently showing a good ability to dwell on the abyss of contradictory or unexpected meanings.

To recall the alchemic scenario, at the end of the intense group work that we call "circulation" (of images, shapes, meanings, analogies) the participants had to transit from the albedo to the rubedo: that means they had to try to give some interpretations of the works of art; extracting a new, different knowledge about the tutor fixing some meanings even if not in a definitive way, and come to a symbolic interpretation of the works. Without coming to a definitive explanation they succeeded in identifying many possible meanings, naming important resonances, and recognising the reticular correspondences between the explored matter and the world of shapes, symbols and archetypes in the works referred to. At the end sparks of knowledge appeared, something different than a corpus of notions, concepts or competences. Perhaps they don't learn something more on tutor but their sensibility in regard of this educative figure, his/her knowledge, languages, action, educative goals symbolic meaning and role in our life became deeper, more complex as it appears in some of the final symbolic pictures they produced. (see fig. 1-2-3-4) 


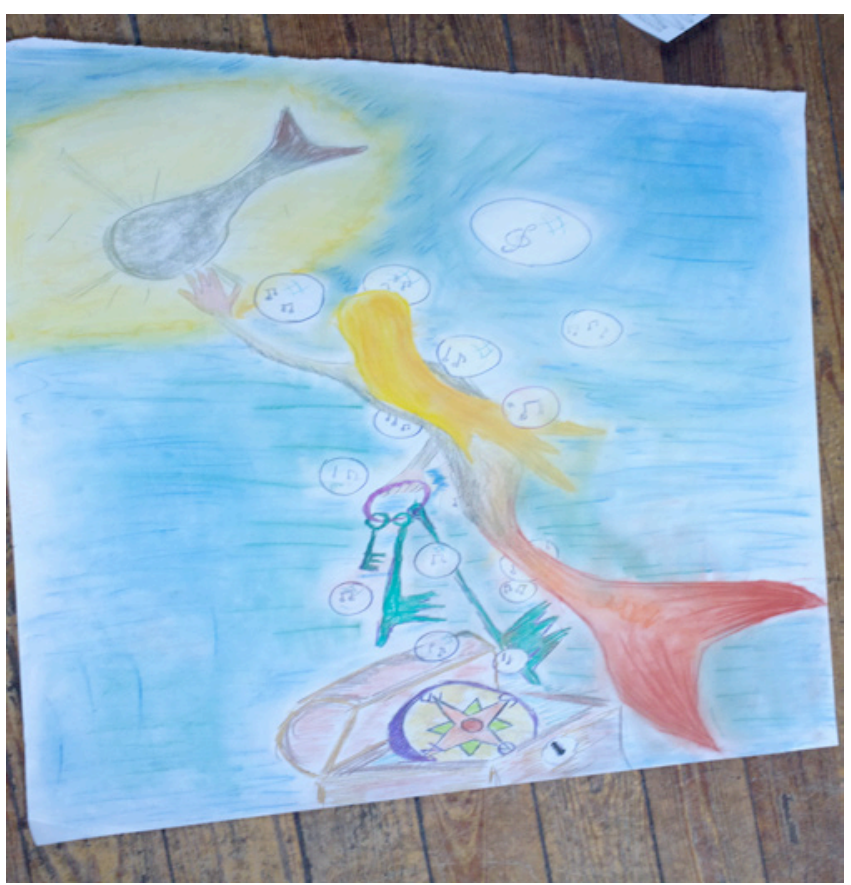

Fig. 1 The Siren.

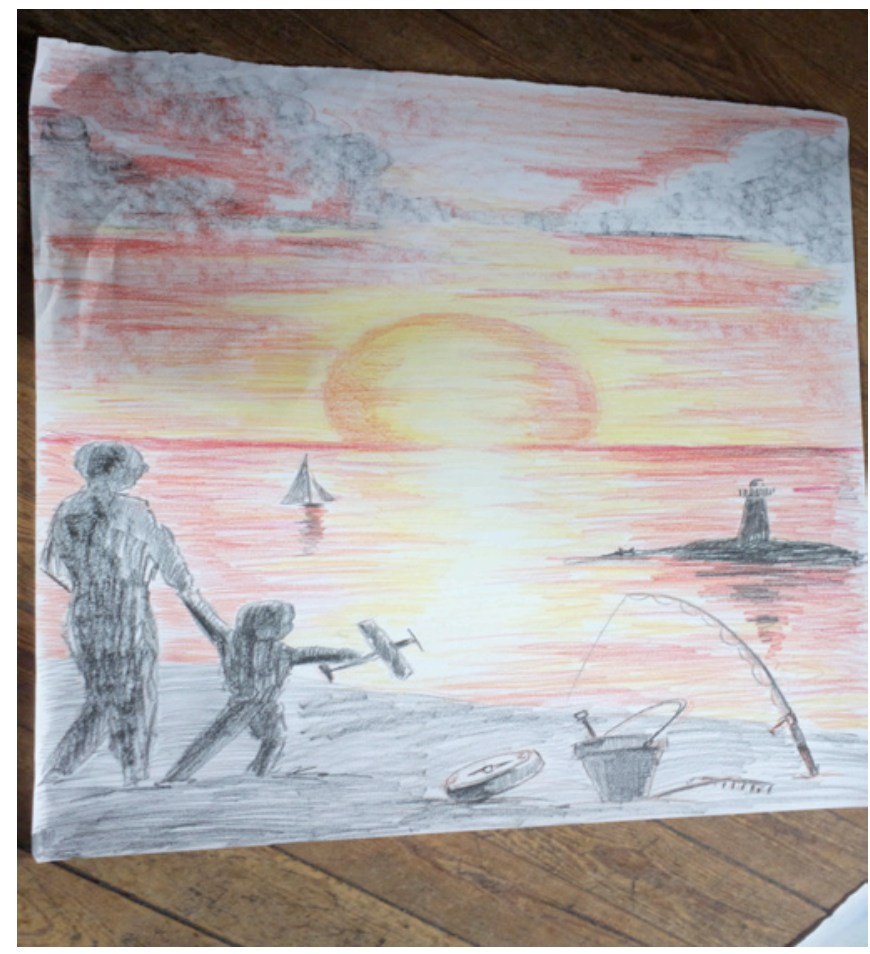

Fig. 2 Childhood knowledge and flying attitude. 


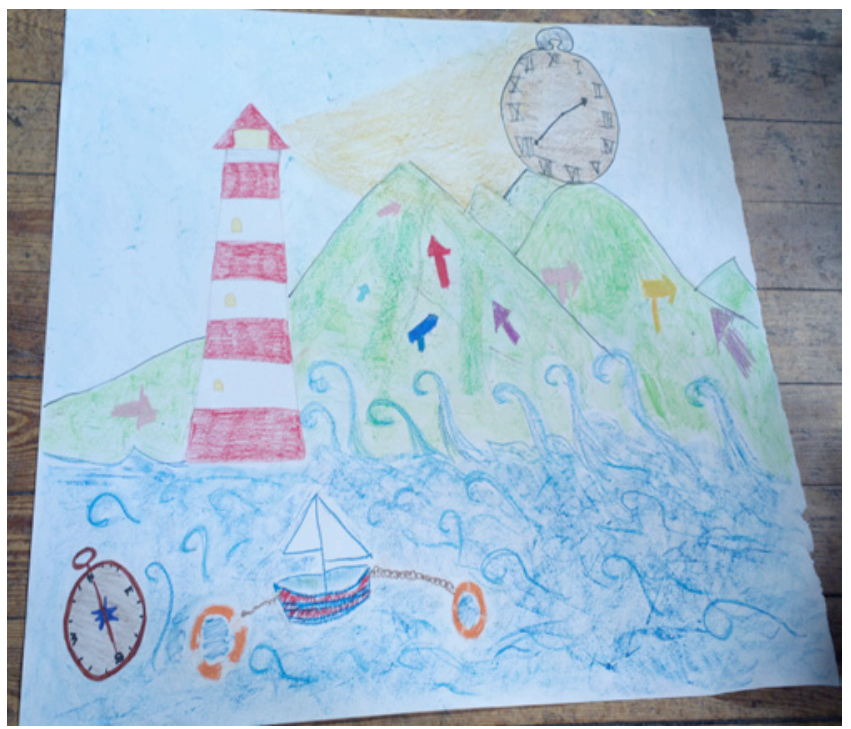

Fig. 3 To the Lighthouse.

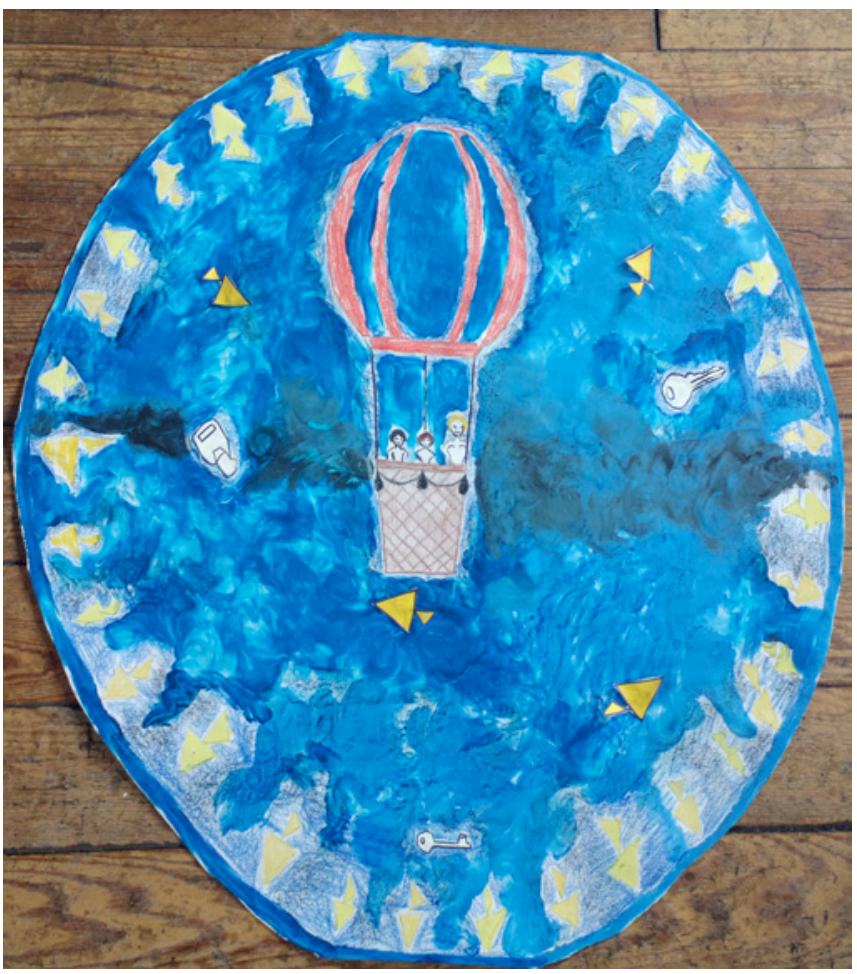

Fig. 4 Mandala in Blue.

But the most important result lies beyond the amount of meanings obtained, which are specifically to be found in the acknowledgement of the imaginal world of art as a world of knowledge, a world much bigger than the single artist's inner world, a huge cultural heritage made of symbols and myths coming from a tradition of centuries, a living spring from which to draw in the proper way the water to renew their culture.

\section{CONCLUSIONS}

These results suggest once more that the imaginal approach can be successfully employed even in the medical educational field, and that the symbolic art it refers to is not just a "didactic tool", but an important cultural spring from which to draw water to revitalise our culture. 


\section{ACKNOWLEDGEMENTS}

This imaginal experience took place thanks to Dr.ssa Patrizia Massariello e Dr. Silvano Gegorino from Turin University who during these years have recognised the value of the imaginal education in the field of Health pedagogy. Thank a lot also to all the tutors who joint the experience and offered their imaginative contribution.

\section{REFERENCES}

[1] G. Bachelard, La poétique de la rêverie, Paris: PUF, 2010.

[2] M. Barioglio, Nel regno dell'immaginazione. Da Jung alla pedagogia immaginale, Bergamo: Moretti e Vitali, 2008.

[3] M. Barioglio, Eros, corpo, notte. Ricerche immaginali, Milano: Mimesis, 2010.

[4] M. Barioglio, Pain Meanings: an imaginal Exploration of Representation of Affliction and Distress in International conference on education Athens: EKPA, 2011, pp. 206-210.

[5] M. Barioglio. La pratica immaginale in G.P. Quaglino (a cura di), Formazione. I metodi, Milano: Cortina 2014, pp. 660-681.

[6] M. Barioglio, P. Mottana, T. Morgigno, Il corpo tra ferita e guarigione: un percorso di ricerca e formazione immaginale, in S. Kanizsa Raccolta degli abstract per la giornata dei poster sulla ricerca, Dipartimento di Scienze Umane per la Formazione "Riccardo Massa", Milano 2015, p. 13.

[7] R. Desoille, Le rêve éveillé dirigé en psychothérapie. Ces étranges chemins de l'imaginaire, Eres, 2000.

[8] F. Bonardel, Philosophie de l'alchimie, Paris: PUF, 1993.

[9] B. Duborgel, Imaginaire er pedagogie, Toulouse: Privat, 1992.

[10] G. Durand, Les structures anthropologiques de l'imaginaire : Introduction à l'archétypologie générale, Paris: Dunod, 2016.

[11] A. Guggenbühl-Craig, The Old Fool and the Corruption of Myth, Spring Pubblication 2015.

[12] J. Hillman, A Blue Fire, London: Routledge, 1990.

[13] C.G. Jung, The Collected Works, Digital Edition: Princenton University Press, 2014.

[14] T. Leonard, P. Willis, Pedagogies of the Imagination. Mythopoietic Curriculum in Educational Practice, USA-Australia: Springer, 2008.

[15] P. Mottana, Miti d'oggi nell'educazione. E opportune contromisure, Milano: Angeli, 2000.

[16] P. Mottana, L'opera dello sguardo. Braci di pedagogia immaginale, Bergamo: Moretti e Vitali, 2002.

[17] P. Mottana, La visione smeraldina, Milano: Mimesis 2004.

[18] P. Mottana, L'arte che non muore. L'immaginale contemporaneo, Milano: Mimesis, 2010.

[19] J. J. Wunenburger, La vie des images. Grenoble: PUG, 2002.

[20] M. Zambrano, Hacia un saber sobre el alma, Madrid: Alianza Editorial, 2012. 